\title{
Effect of soil stiffness on seismic response of reinforced concrete buildings with shear walls
}

\author{
B. R. Jayalekshmi ${ }^{1} \cdot$ H. K. Chinmayi ${ }^{1}$
}

Received: 24 June 2015 / Accepted: 15 February 2016/Published online: 29 March 2016

(C) Springer International Publishing Switzerland 2016. This article is published with open access at Springerlink.com

\begin{abstract}
Buildings are subjected to lateral loads caused by wind, blasting and earthquakes. The high stresses developed by these loads literally tear the building components apart, which are in general designed for gravity loads. To resist these lateral forces, shear walls can be introduced in buildings. Present study aims to determine the apt shear wall position which attracts the least earthquake forces in symmetric plan multi-storey buildings. Dynamic response of a structure is significantly influenced by the underlying soil due to its natural ability to deform. Three dimensional finite element soil-structure interaction analyses of reinforced concrete shear wall buildings with shear walls placed at various locations is carried out in time domain using scaled down Elcentro ground motion to determine the seismic response variation in the structure due to the effect of stiffness of soil. Four different soil types based on shear wave velocity and six varying shear wall positions in multi-storey buildings up to 16 storeys are considered to determine the effect of soil-structure interaction. From the study, it is found that structural response as per conventional fixed base condition is very conservative. For buildings founded on soil with $\mathrm{V}_{\mathrm{s}} \leq 300 \mathrm{~m} / \mathrm{s}$, providing the shear walls at the core is advantageous whereas for soil with $\mathrm{V}_{\mathrm{s}}>300 \mathrm{~m} / \mathrm{s}$, the shear walls placed at exterior corners of the building attracts the least earthquake force.
\end{abstract}

Keywords Soil-structure interaction - Shear wall · Finite element method . Transient analysis

B. R. Jayalekshmi

br.jaya@gmail.com

1 National Institute of Technology Karnataka, Mangalore, India

\section{Introduction}

Soil-structure interaction (SSI) is an interdisciplinary field which involves structural and geotechnical engineering. The dynamic response of a structure depends on the properties of underlying soil, structure and nature of excitation. The process in which, the response of the soil influences the motion of the structure and vice versa, is referred to as SSI.

The conventional non-interaction analysis of buildings without considering the influence of the soil results in design which is either unnecessarily costly or unsafe. Hence the interaction between the structure and the soil need to be considered and modelled accurately in order to design earthquake resistant structures and to evaluate the seismic safety of the building. SSI problem has become a significant feature in structural engineering as it is inevitable to build important structures in locations with less favourable geotechnical conditions like seismically active regions.

For the structures founded on rock, the extreme high stiffness of the rock constrains the rock motion and the structural response is regarded to be same as that of a fixed base structure during ground motion. The same structure responds differently when supported on a soft soil. The motion of the base of the structure diverges from the free field motion, due to the incompetence of the foundation to adapt to the deformations of the free field. Besides, dynamic response of the structure induces deformation of the supporting soil. The response of the soil regulates the motion of the structure and the response of the structure regulates the motion of the soil. This process is generally referred to as dynamic soil-structure interaction.

When the supporting medium of soil is considered in the analysis, the dynamic characteristics of structural system 
get altered when compared to those with the conventional completely restrained supports, as soil forms the constitutional part of the structure. Significant modifications in dynamic response are reflected in terms of stress components and deflections, from the expected behaviour of the structural system on a rigid support.

At the beginning, SSI has been viewed as beneficial during seismic motion, but changing research trends has resulted in different notions about the phenomenon. Despite the fact that SSI increases damping which is beneficial it also causes additional displacement to the overall structure which has detrimental effects.

Gazetas and Mylonakis [9] noticed that supporting soil medium allows certain movements due to its natural flexibility which decreases the overall stiffness of the structural system and increases the natural periods of the system. The study also highlighted the influence of partial fixity of structures at the foundation level due to soil flexibility altering the response. Studies carried out by Kobayashi et al. [10], Stewart et al. [16], Gazetas and Mylonakis [9] state that SSI can be detrimental and neglecting its influence could lead to unsafe design for both the superstructure and the foundation, especially for structures on soft soil deposits.

Balendra and Heidebrecht [3] and Veletsos and Prasad [18] demonstrated the significance of SSI effects in medium and long period structures. Recent recorded earthquake spectra prove that SSI turns to be a significant factor for the maximum acceleration occurring at a period greater than $1.0 \mathrm{~s}$. If the fundamental period is lengthened due to SSI, it would increase the response rather than decreasing it, which goes against the conventional design spectra. Studies of Bucharest earthquake 1977, Mexico earthquake 1985 and Kobe earthquake 1995 showed an increase in the seismic response of structures despite a possible increase in damping as reported by Gazetas and Mylonakis [9]. Authors also reported that the Mexico earthquake was particularly destructive to 10-12 storey unbraced buildings founded on soft clay, for which period increased from about $1.0 \mathrm{~s}$ (as per conventional fixed base assumption) to nearly $2.0 \mathrm{~s}$ due to the SSI.

A comprehensive study including SSI effects carried out by Stewart et al. [16] for 77 strong motion data sets at 57 actual building sites that cover a wide range of structural and geotechnical conditions revealed that inertial SSI effects can be conveyed by a fundamental natural period lengthening ratio and foundation damping factor. Accordingly, the fundamental natural period of the overall system and total damping are increased by considering SSI effects.

Effect of SSI in increasing the lateral deflections and corresponding inter-storey drifts of the structure, pushing the structure to behave in the inelastic range, resulting in severe damage of the structure was studied by Sivakumaran and Balendra [15], Alavi and Krawinkler [2],
Adam et al. [1], Galal and Naimi [8], Massumi and Tabatabaiefar [13] and Tavakoli et al. [17]. A numerical study on low-rise unbraced buildings up to 6 stories adopting Winkler method of soil modelling was carried out by Dutta et al. [7] showing that, generally, in low-rise unbraced buildings the lateral natural period is very small and may lie within the sharply increasing zone of response spectrum. Hence, an increase in lateral natural period due to the effect of SSI may cause an increase in the spectral acceleration ordinate. Author concluded that the effect of SSI may play a significant role in increasing the seismic base shear of low-rise building frames. However, seismic response generally decreases due to the influence of SSI for medium to high rise buildings. Bhattacharya et al. [6] carried out the SSI analysis of lowrise buildings to determine the dynamic behaviour of building frames on raft foundation due to the effect of SSI. Considerable variation in lateral natural periods and base shear were found signifying the need of incorporating the effect of SSI on the seismic analysis of buildings. The effect of SSI on stress resultants experienced by the raft and the interface between the rock and raft of massive concrete structures supported over raft foundation was carried out by Rajasankar et al. [14].

Present study focuses on the three-dimensional SSI analysis of multi storied RC buildings with shear walls at various locations over raft foundation subjected to modified Elcentro ground motion in time domain. Finite element method was utilized to evaluate the seismic responses in structure. Advantages of various locations of shear walls and the effect of stiffness of underlying soil are investigated. This study determines the apt shear wall location which attracts the least earthquake forces in symmetric plan multi-storey buildings founded on different ground types in moderate seismic intensity region.

\section{Soil-structure interaction analysis by direct method}

SSI is an interdisciplinary field of strive. It combines structural mechanics, soil dynamics, structural dynamics, earthquake engineering, geophysics and geomechanics, material science, computational and numerical methods and other various technical disciplines. Its lineage draws back to the late nineteenth century, evolving and maturing in a gradual manner in the ensuing decades and during the first half of the twentieth century. SSI advanced rapidly during the second half, accelerated mainly by the needs of the nuclear power and offshore industries, by the introduction of powerful computers and simulation tools such as finite elements and by the desire for improvements in seismic safety. 


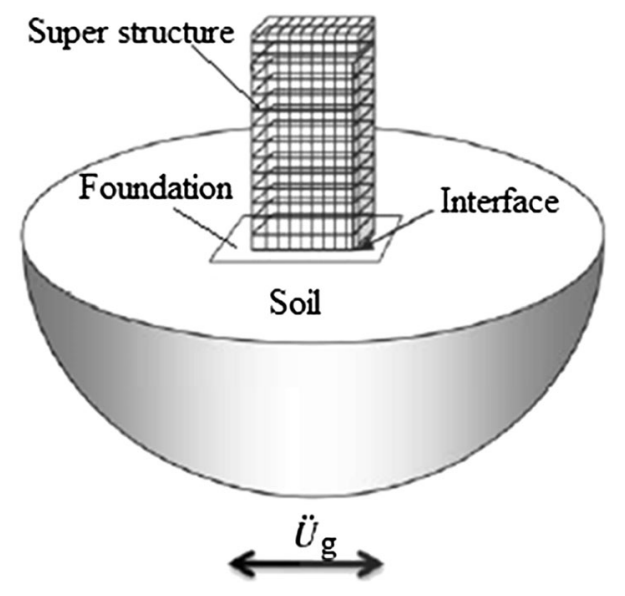

Fig. 1 Soil-structure system in direct method

Considering the modelling methods incorporating soil region, SSI problems are classified into two main categories, namely direct method and substructure method. In direct method, response of the entire structure foundationsoil system is analysed in a single step. However, in substructure method, analysis of parts of whole structural system is performed in several steps and the final response is based on the principle of superposition.

Direct method of SSI analysis has been followed in the study. In direct method, the modelling and analysis of the entire structure-foundation-soil system is carried out in a single step. The structure and a finite bounded soil zone adjacent to the structure (near field) are modelled and the effect of the surrounding unbounded soil (far field) is analysed approximately by imposing the transmitting boundaries along the near-field/far-field interface to prevent the reflection of stress waves at the artificially introduced boundaries. Structure-foundation-soil system modelled using direct method consists of super structure, foundation, unbounded soil, interface between foundation and soil and earthquake induced acceleration at the level of the bed rock, is as shown in Fig. 1.

A computer program which treats the behaviour of both soil and structure with equal rigor simultaneously is a necessity in direct method of analysis (Kramer [11]). Hence, finite element software LS-DYNA is employed to model the soil-structure system and to solve the equations for the complex geometries and boundary conditions.

\section{Idealization of structural and geotechnical model}

\section{Structural idealization}

To examine the dynamic behaviour while considering the effect of soil-structure interaction, reinforced concrete building frames of aspect ratio [height-to-base ratio of
Table 1 Dimensions of components of building

\begin{tabular}{llll}
\hline AR & Columns $(\mathrm{m})$ & $\begin{array}{l}\text { Shear wall } \\
\text { thickness }(\mathrm{m})\end{array}$ \\
\cline { 2 - 3 } & Up to 3 storey & Above 3 storey & \\
\hline 1 & $0.32 \times 0.32$ & $0.32 \times 0.32$ & 0.15 \\
1.5 & $0.35 \times 0.35$ & $0.35 \times 0.35$ & 0.15 \\
2 & $0.40 \times 0.40$ & $0.35 \times 0.35$ & 0.20 \\
3 & $0.50 \times 0.50$ & $0.40 \times 0.40$ & 0.20 \\
4 & $0.60 \times 0.60$ & $0.50 \times 0.50$ & 0.25 \\
\hline
\end{tabular}

Raft foundation slab: $0.3 \mathrm{~m}$, roof and floor slab: $0.15 \mathrm{~m}$, beams: $0.23 \times 0.23 \mathrm{~m}$

building (AR)] 1, 1.5, 2, 3 and 4 corresponding to 4, 6, 8, 12 and 16 storey with and without shear walls were idealized as 3D space frames using Belytschko-Schwer resultant beam element having three translational and three rotational degrees of freedom at each node. The roof slab, floor slabs, shear walls and foundation slab of adequate thickness were modelled using four-node shell element Belytschko-Tsay having bending and membrane capabilities. Belytschko-Tsay shell element possesses six degrees of freedom at each node. Building components were discretized using beam elements and shell elements with fine mesh of element size $1 \mathrm{~m}$. The storey height and length of each bay were chosen as 3 and $4 \mathrm{~m}$ respectively which is reasonable for domestic or small office buildings. The dimensions of building components were arrived at on the basis of structural design adopting the respective Indian standard codes for design of reinforced concrete structures IS 456:2000 and IS 13920:1993. Dimensions of building components are as shown in Table 1 .

Reinforced concrete buildings with various shear wall locations (middle bay of exterior frame, at core, at two opposite corners, at exterior bays, at all four corners and at the middle bay) while maintaining the mass added due to these shear walls to be the same, were considered. The thickness of shear wall was varied from 150-250 mm depending on the building height. The materials considered for the design of structural elements were concrete of grade M20 and Fe415 grade steel. The idealized form of a typical 3 bay $\times 3$ bay frame with different shear wall locations is represented schematically in Fig. 2.

\section{Geotechnical idealization}

3D soil stratum was modelled with eight-node fully integrated solid element having three translational degrees of freedom at each node. To overcome the node incompatibility problem occurring between the soil and structure, a tied surface to surface contact (*INTERFACE) between the soil surface and base of the structure was employed such that the translational motion of soil due to bending of 
Fig. 2 Plan of building frame with shear walls at various locations

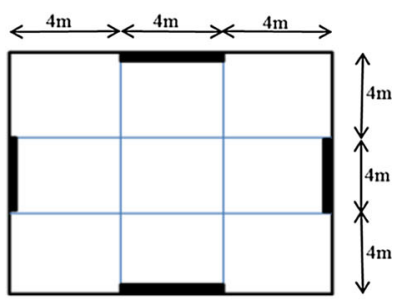

SW1

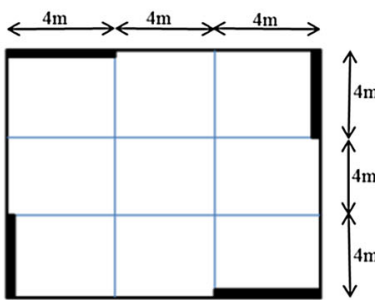

SW4

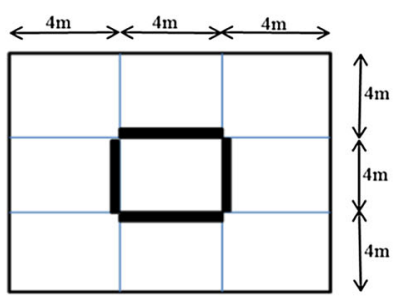

SW2

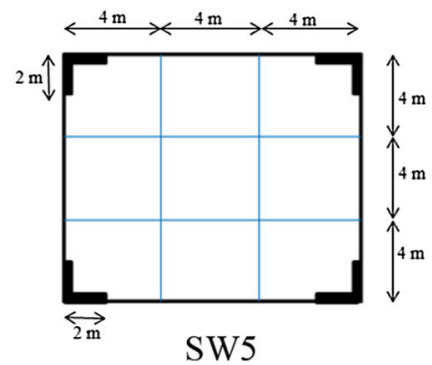

SW5

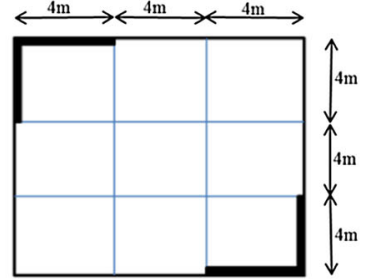

SW3

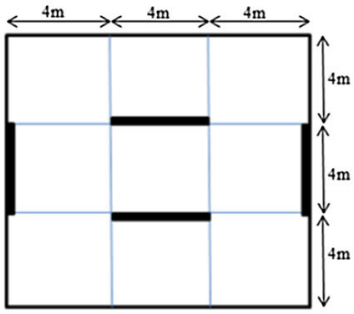

SW6

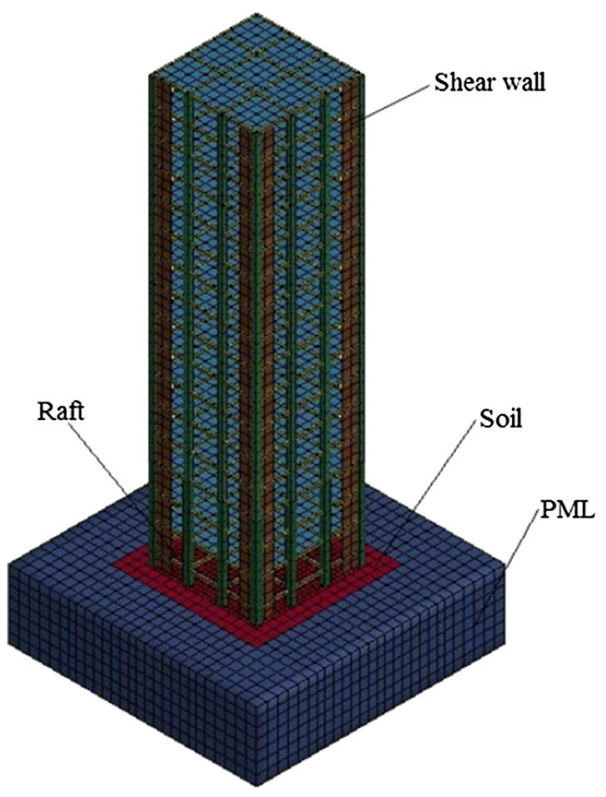

raft was imposed and the raft and soil were coupled effectively. Soil medium was discretized with solid elements of $1 \mathrm{~m}$ size along lateral direction and depth.

To analyse the soil-foundation and structure, soil was treated as an isotropic, homogenous and elastic half space medium. In linear SSI analysis, properties of the soil stratum are defined by its mass density, elastic modulus and Poisson's ratio. The width of the soil mass beyond the raft was considered as $0.2 \mathrm{~B}$ and depth as $0.2 \mathrm{~B}$, where $\mathrm{B}$ is the half width of the raft [4]. In order to simulate the wave propagation in an unbounded soil medium, an absorbing layer material called Perfectly-Matched Layer (PML) material with a thickness of $0.8 \mathrm{~B}$ beyond the soil layer was considered [4]. The various input parameters for the PML remain same as that of the corresponding equivalent linearelastic soil as given in Table 2.

The study primarily attempts to identify the effects of SSI on buildings resting on different types of non-cohesive soil, viz., soft, stiff, dense and rock. The details of different soil parameters considered in the study in accordance with FEMA 273 are as tabulated in Table 2. Three dimensional finite element model of the integrated soil-foundation-

Table 2 Details of soil parameters

\begin{tabular}{lllll}
\hline $\begin{array}{l}\text { Soil } \\
\text { profile } \\
\text { type }\end{array}$ & Description & $\begin{array}{l}\text { Shear wave } \\
\text { velocity } \\
\left(\mathrm{V}_{\mathrm{s}}\right)(\mathrm{m} / \mathrm{s})\end{array}$ & $\begin{array}{l}\text { Poisson's } \\
\text { ratio }\end{array}$ & $\begin{array}{l}\text { Unit weight }(\rho) \\
\left(\mathrm{kN} / \mathrm{m}^{3}\right)\end{array}$ \\
\hline $\mathrm{S}_{\mathrm{b}}$ & Rock & 1200 & 0.3 & 22 \\
$\mathrm{~S}_{\mathrm{c}}$ & Dense soil & 600 & 0.3 & 20 \\
$\mathrm{~S}_{\mathrm{d}}$ & Stiff soil & 300 & 0.35 & 18 \\
$\mathrm{~S}_{\mathrm{e}}$ & Soft soil & 150 & 0.4 & 16 \\
\hline
\end{tabular}

Fig. 3 Idealised 3D finite element model of soil-foundation-structure system

structure system generated using finite element software LS-DYNA is as shown in Fig. 3.

\section{Perfectly matched layer (PML) concept}

To symbolize the unbounded soil domain in an effective and precise manner, perfectly matched layer (PML) concept has been adopted in the study. PML is a wave absorbing layer which, when placed adjacent to a truncated model of an unbounded domain absorbs and attenuates all waves outgoing from it. The continuum PML is mathematically formulated by applying a complex-valued 
coordinate stretching to the elastic wave equation such that the waves of all frequencies and all angles of incidence are absorbed into the PML without any reflection from the interface. The PML is thus 'perfectly matched' to the truncated domain. This novel property of the PML makes it fundamentally different and more attractive than traditional local absorbing boundaries or layers, even though it itself is a local formulation. Choosing a particular form of the coordinate stretch in terms of an attenuation function allows the PML to attenuate the wave inside the layer. The attenuated wave is reflected back towards the truncated domain from the outer boundary of the PML which may be a fixed boundary but the amplitude of the reflected wave re-entering the domain can be made arbitrarily small by an appropriate choice of the attenuation function. Thus, any outgoing wave is only minimally reflected back, making the PML an appropriate model for the unbounded domain beyond. PML approach in general is applicable to any linear wave equation and elastic waves as it produces highly accurate results at low computational cost.

\section{Finite element formulation of PML in time domain}

The governing equations of motion for the structure incorporating soil interaction are relatively complex. The dynamic equilibrium equation depicting the motion of structure subjected to a transient external load can be written as

$[M]\{\ddot{u}\}+[C]\{\dot{u}\}+[K]\{u\}=\left\{F_{d y n}\right\}+\left\{F_{s t}\right\}$

where, $[\mathrm{M}],[\mathrm{C}],[\mathrm{K}]$ are characteristic matrices for consistent mass, damping and stiffness of a system. $\left\{\mathrm{F}_{\mathrm{st}}\right\}$ is the pre-dynamic load vector including the self-weight of the structure and $\left\{\mathrm{F}_{\mathrm{dyn}}\right\}$ is the dynamic load vector. $\{\mathrm{u}\}$ is the vector of nodal displacements and a super imposed dot indicates the time derivative.

To simulate infinite soil regions in study, FE based PML formulation following the displacement based approach introduced by Basu and Chopra [5] is employed. The governing equations for PML domain are found by means of a coordinate transformation involving stretching function determined with complex numbers. Governing Equations for time domain finite element PML formulation is given by

$$
\left[M_{P M L}\right]\{u\}+\left[C_{P M L}\right]\{\dot{u}\}+\left[K_{P M L}\right]\{u\}+\left\{f_{P M L}^{\text {int }}\right\}=\left\{f_{P M L}^{e x t}\right\}
$$

where, $\left[M_{P M L}\right],\left[C_{P M L}\right]$ and $\left[K_{P M L}\right]$ represent the mass, damping and stiffness matrices for a PML medium modulated by stretching functions for evanescent waves. $f_{P M L}^{\text {int }}$ is internal force vector and $f_{P M L}^{e x t}$ represents the true external forces to the PML domain.

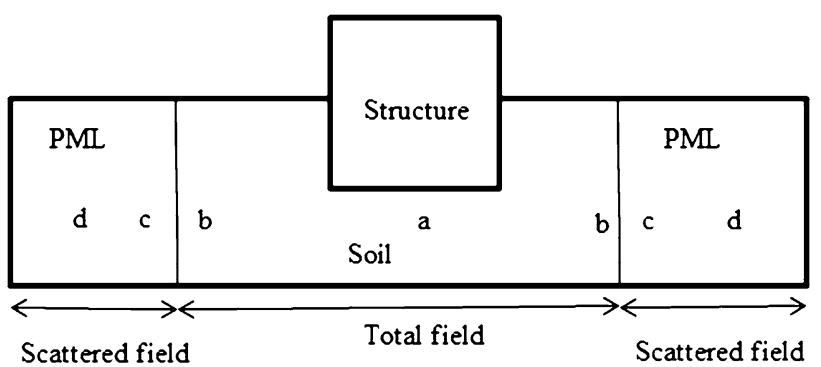

Fig. 4 Partition of DOF's of SSI system

A computational model of structure-soil system considered is as shown in Fig. 4 [11], where the soil region is of infinite extent in the horizontal directions and thus PMLs are rendered outside the region of interest.

For considering seismic excitation, the domain is divided into two regions, one where the field variables are expressed in total motion and the other in scattered motion. Scattered field motion $u^{\mathrm{s}}$ is defined as the difference between the total and free field motion.

$\mathrm{u}^{\mathrm{s}}=\mathrm{u}-\mathrm{u}^{\mathrm{f}}$,

where, free-field motion $u^{f}$ is the motion of the soil deposit (due to an earthquake under consideration) without any structure on it and ' $\mathrm{u}$ ' is the total motion.

For the region expressed by the total field, the equations of motion are written as

$$
\begin{gathered}
{\left[\begin{array}{cc}
M_{a a} & 0 \\
0 & M_{b b}
\end{array}\right]\left\{\begin{array}{l}
\ddot{u}_{a} \\
\ddot{u}_{b}
\end{array}\right\}+\left[\begin{array}{ll}
C_{a a} & C_{a b} \\
C_{b a} & C_{b b}
\end{array}\right]\left\{\begin{array}{l}
\dot{u}_{a} \\
\dot{u}_{b}
\end{array}\right\}} \\
+\left[\begin{array}{cc}
K_{a a} & K_{a b} \\
K_{b a} & K_{b b}
\end{array}\right]\left\{\begin{array}{l}
u_{a} \\
u_{b}
\end{array}\right\}=\left\{\begin{array}{c}
0 \\
F_{b}
\end{array}\right\}
\end{gathered}
$$

where, the subscript ' $b$ ' refers to the DOFs on the interface within soil between the total and scattered field and subscript ' $a$ ' denotes DOFs within total field.

Similarly, the scattered-field region is governed by

$$
\begin{gathered}
{\left[\begin{array}{cc}
M_{c c} & 0 \\
0 & M_{d d}
\end{array}\right]\left\{\begin{array}{l}
\ddot{u}_{c} \\
\ddot{u}_{d}
\end{array}\right\}+\left[\begin{array}{ll}
C_{c c} & C_{c d} \\
C_{d c} & C_{d d}
\end{array}\right]\left\{\begin{array}{l}
\dot{u}_{c} \\
\dot{u}_{d}
\end{array}\right\}} \\
+\left[\begin{array}{cc}
K_{c c} & K_{c d} \\
K_{d c} & K_{d d}
\end{array}\right]\left\{\begin{array}{l}
u_{c} \\
u_{d}
\end{array}\right\}=\left\{\begin{array}{c}
F_{c} \\
0
\end{array}\right\}
\end{gathered}
$$

where, the subscript ' $c$ ' refers to the DOFs on the interface within PML between the total and scattered field and subscript ' $d$ ' denotes DOFs within scattered field.

To combine Eqs. 4 and 5 and to invoke the interface relation between the total displacement and scattered field displacement,

$\mathrm{u}_{\mathrm{b}}=\mathrm{u}_{\mathrm{c}}+\mathrm{u}^{\mathrm{f}}$

and the balance of interaction forces as

$\mathrm{F}_{\mathrm{b}}=-\left(\mathrm{F}_{\mathrm{c}}+\mathrm{F}^{\mathrm{f}}\right)$ 
where, $\mathrm{F}^{\mathrm{f}}$ is the equivalent nodal force due to free-field motion.

The combined equation of Eqs. 6 and 7 is written as

$$
\begin{aligned}
& {\left[\begin{array}{ccc}
M_{a a} & 0 & 0 \\
0 & M_{b b}+M_{c c} & 0 \\
0 & 0 & M_{d d}
\end{array}\right]\left\{\begin{array}{l}
\ddot{u}_{a} \\
\ddot{u}_{b} \\
\ddot{u}_{d}
\end{array}\right\}+\left[\begin{array}{ccc}
C_{a a} & C_{a b} & 0 \\
C_{b a} & C_{b b}+C_{c c} & C_{c d} \\
0 & C_{d c} & C_{d d}
\end{array}\right]\left\{\begin{array}{l}
\dot{u}_{a} \\
\dot{u}_{b} \\
\dot{u}_{d}
\end{array}\right\}} \\
& +\left[\begin{array}{ccc}
K_{a a} & K_{a b} & 0 \\
K_{b a} & K_{b b}+K_{c c} & K_{c d} \\
0 & K_{d c} & K_{d d}
\end{array}\right]\left\{\begin{array}{l}
u_{a} \\
u_{b} \\
u_{d}
\end{array}\right\}=\left\{\begin{array}{c}
M_{c c} \ddot{u}^{f}+C_{c c} u^{f}+K_{c c} u^{f} \\
C_{d c} \dot{u}^{f}+K_{d c} u^{f}
\end{array}\right\}+\left\{\begin{array}{r}
0 \\
-F^{f} \\
0
\end{array}\right\}
\end{aligned}
$$

The effect of seismic excitation included as external forces to the discrete structure-soil system is as shown in Eq. 8 .

\section{Idealization of soil-structure interface}

The FE program LS-DYNA has a unique feature for defining the interface between soil and structure accurately. The keyword *INTERFACE_SSI_ID is used for defining the soil-structure interface. For this, first a structure segment is defined for base of the structure at soil-structure interface and a soil segment is defined for soil surface at soil-structure interface. A tied contact interface is created between the structure and the soil using the specified segment sets, with the soil segment set as the master and the structure segment set as the slave. The two segment sets should not have merged nodes and can be non-matching in general. However, the area covered by the two surfaces should match. The free field earthquake ground motions are specified at certain locations defined by either nodes or coordinates on a soil-structure interface. The specified motions are not imposed directly at the nodes, but are used

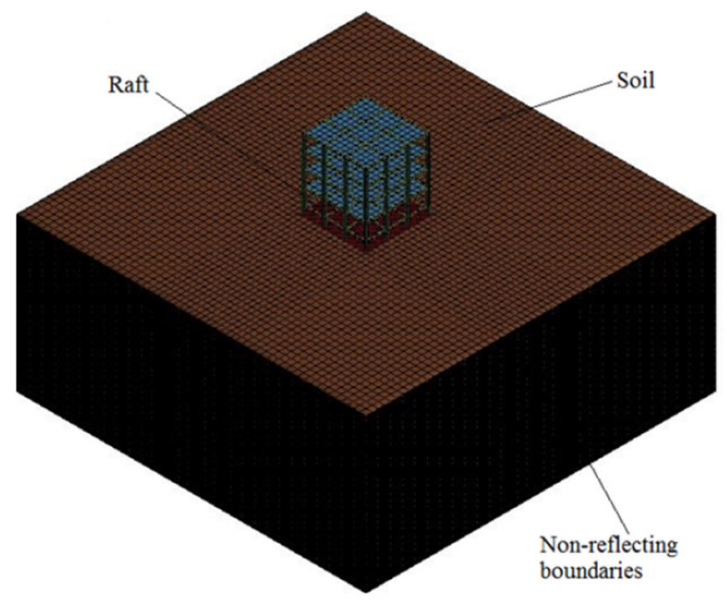

(a) Non-reflecting boundaries to compute a set of effective forces in the soil elements adjacent to the soil-structure interface according to the effective seismic input-domain reduction method. This SSI interface between the soil surface and base of the structure is employed in the present study such that the raft and soil are coupled effectively.

\section{Validation of SSI system with PML}

An investigation on FE model of a four storey bare frame building with supporting unbounded soil medium represented in the form of elastic continuum with (1) non-reflecting boundaries and (2) PML was carried out as a numerical example to determine the computational cost. Finite element model of idealized soil-structure system of typical four storey building with non-reflecting boundaries and PML model are as shown in Fig. 5.

Elastic continuum model with non-reflecting boundaries are composed entirely of elastic element modelled with eight-node fully integrated S/R solid having three translational degrees of freedom at each node. The boundary elements at the bottom were restricted from translations. The lateral vertical soil boundaries were modelled with non-reflecting elements. The width and thickness of the soil medium beyond foundation were taken as 1.5 times and 2 times the least width of the raft foundation to ensure that waves reflected back from the outer boundary modelled using non-reflecting boundaries do not affect the results of the simulation [12]. In PML model, the width and depth of the soil mass beyond the foundation were considered as $0.2 \mathrm{~B}$, where $\mathrm{B}$ is the half width of the foundation [4]. In order to simulate the wave propagation in an unbounded soil medium, perfectly matched layer (PML) material with a thickness of $0.8 \mathrm{~B}$ beyond the soil layer was considered

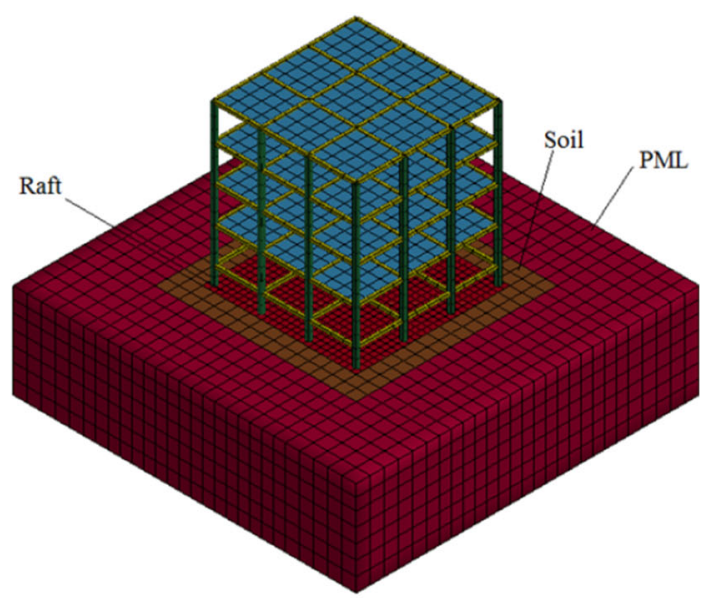

(b) PML model

Fig. 5 Finite element model of idealized soil-structure system of typical 4 storey building 
[4]. The node incompatibility occurring between soil and structure due to varying degrees of freedom of shell element and solid element is overcome by soil-structure interface, a tied surface to surface contact.

Comparison of computational cost to determine the efficiency of these two models to represent infinite soil in seismic analysis was carried out. It was noticed that the number of elements and computational time required in SSI analysis with PML soil model are significantly lesser than elastic continuum model with non-reflecting boundaries. The number of solid elements used to model infinite soil in elastic continuum model with non-reflecting boundaries was 87,025 where as in PML only 5103 solid elements were sufficient. The total number of elements employed in analysis using elastic continuum model with non-reflecting boundaries were 88,506 and for PML model were 6579 and the computation time taken by these models were 19 and $2 \mathrm{~h}$ respectively.

The comparison of seismic responses of structural elements in these two models is shown in Fig. 6. The fundamental natural period of the SSI system obtained from the model with non-reflecting boundaries is $0.987 \mathrm{~s}$ and from the PML model is $0.990 \mathrm{~s}$. The values of seismic response obtained by employing these two soil models are tabulated in Table 3. From Table 3, it is evident that seismic response values obtained from both the models are identical except for base shear where PML soil model gives slightly higher value ( $<1 \%$ variation) than elastic continuum with non-reflecting boundaries. By comparing the computational costs of the two models PML model is found to be more efficient, hence it is adopted in the analysis of SSI system.

\section{Methodology}

Transient analysis is the most accurate method in determining the seismic response of structures. It is the technique used to determine the dynamic response of structures under the action of time dependent loads. The dynamic equilibrium equation describing the motion of structure subjected to a transient external load can be written as given in Eq. 1.

Transient analysis was carried out on integrated SSI systems of multi-storey reinforced concrete shear wall buildings of aspect ratio 1, 1.5, 2, 3 and 4 with different shear wall locations as shown in Fig. 2. An artificial ground motion corresponding to the longitudinal component of Imperial Valley earthquake at Elcentro (1940), with peak ground acceleration (PGA) scaled down to $0.1 \mathrm{~g}$ (total duration of ground motion is $60 \mathrm{~s}$ ) was used. This modified ground motion is designated as 'Elcentro1'. The time history and corresponding Fourier spectrum of Elcentro1 ground motion are as shown in Figs. 7 and 8. This ground motion contains strong frequency contents in the natural frequency range of the structures considered.

\section{Results and discussions}

Seismic SSI analysis was conducted on RC shear wall buildings with raft foundation using the time history record of Elcentro ground motion with its peak ground acceleration (PGA) scaled down to $0.1 \mathrm{~g}$ assuming linearly elastic material behaviour for soil and structure. Building models with various shear wall configurations were analysed to find out the apt configuration. The transient analysis responses in 140 SSI models were analysed. The variations in dynamic characteristics and seismic response of the structure by the incorporation of the effect of stiffness of underlying soil were studied and are expressed in terms of absolute maximum responses of base shear, roof deflection, axial force, bending moment and shear forces. The variations in responses of shear wall buildings with flexible base in comparison with conventional fixed base were also computed.

\section{Natural period of buildings}

Fundamental natural periods are determined by Eigen value analyses of integrated SSI systems. The Fig. 9 represents the fundamental lateral natural period of shear wall buildings with shear walls at various locations incorporating the effect of SSI.

The natural periods of buildings resting over soil types $S_{b}$ and $S_{c}$ are very close to the fixed base condition. However, with increase in flexibility of soil, i.e., in $S_{d}$ and $\mathrm{S}_{\mathrm{e}}$, the natural period obtained is higher than the fixed base condition. Natural periods obtained for shear wall buildings are lower than bare frame buildings as the addition of shear wall increases the stiffness of building there by reducing the natural period.

From Fig. 9 it is observed that SW2 configuration (shear wall at the core) has the lowest natural period and SW5 configuration (shear wall at the corners) has the highest natural period making them the stiffest and the most flexible shear wall building respectively.

The percentage variation in natural period increases with increase in flexibility of soil. The increase in natural period is observed to be more in case of bare frame buildings when compared to shear wall buildings for rock and dense soil. However, for stiff and soft soil the increase in natural period is higher in case of shear wall buildings when compared to bare frame buildings. This variation pattern shows that when both the building and soil type are either 
Fig. 6 Comparison of seismic responses in elastic continuum model with (1) PML and (2)

Non-reflecting boundaries

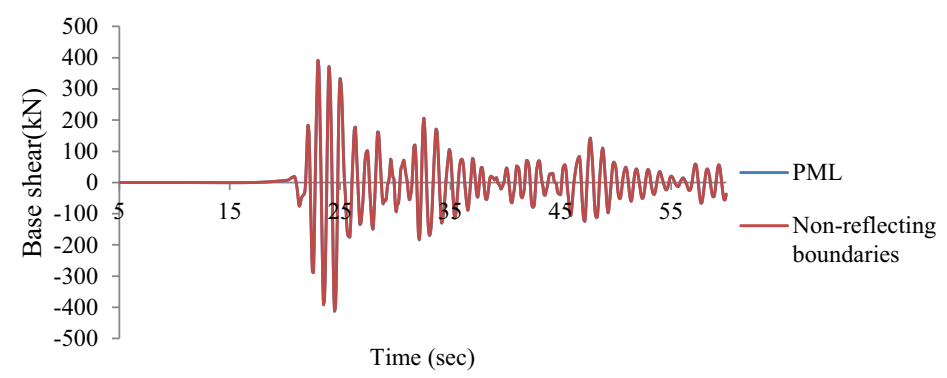

(a) Seismic base shear

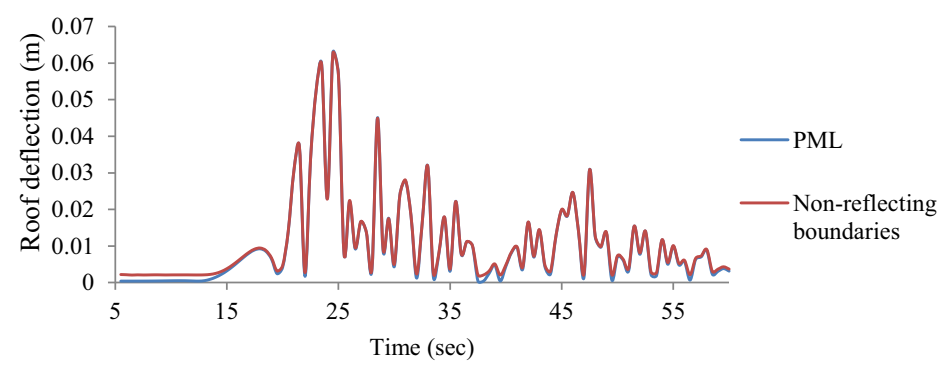

(b) Roof deflection

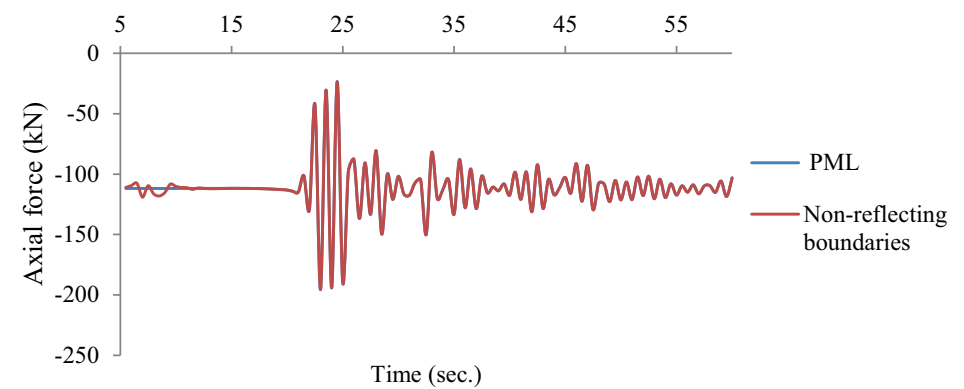

(c) Axial force in column

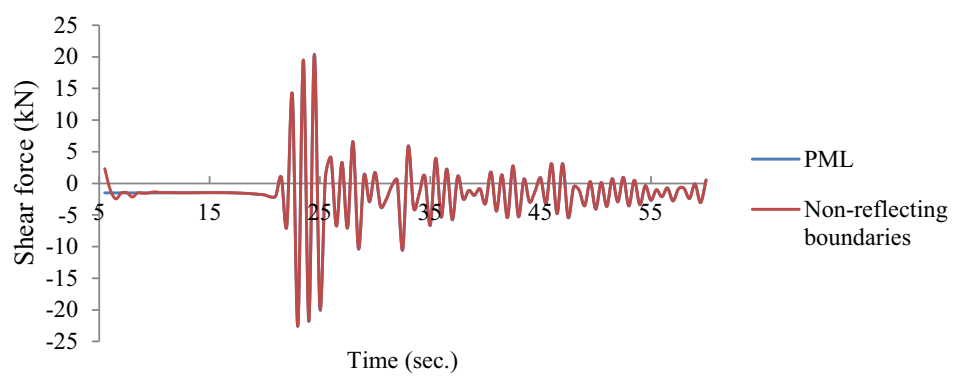

(d) Shear force in column

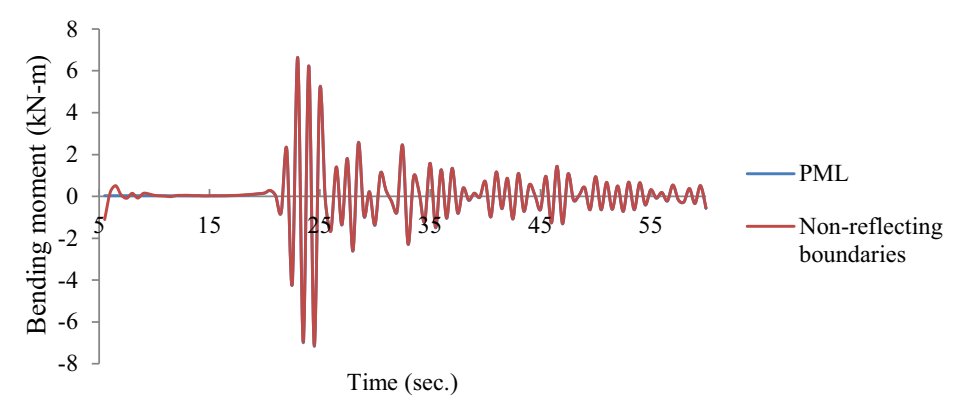

(e) Bending moment in column 
Table 3 Comparison of structural seismic responses

\begin{tabular}{lcc}
\hline Seismic response & \multicolumn{2}{l}{ Elastic continuum soil model } \\
\cline { 2 - 3 } & Non-reflecting boundaries & PML \\
\hline Base shear $(\mathrm{kN})$ & 408.82 & 411.64 \\
Roof deflection $(\mathrm{m})$ & 0.0626 & 0.0628 \\
Axial force of ground floor corner column $(\mathrm{kN})$ & 195.44 & 195.63 \\
Shear force of ground floor corner column $(\mathrm{kN})$ & 22.5 & 22.6 \\
Bending moment of ground floor corner column $(\mathrm{kN} \mathrm{m})$ & 7.13 & 7.17 \\
\hline
\end{tabular}

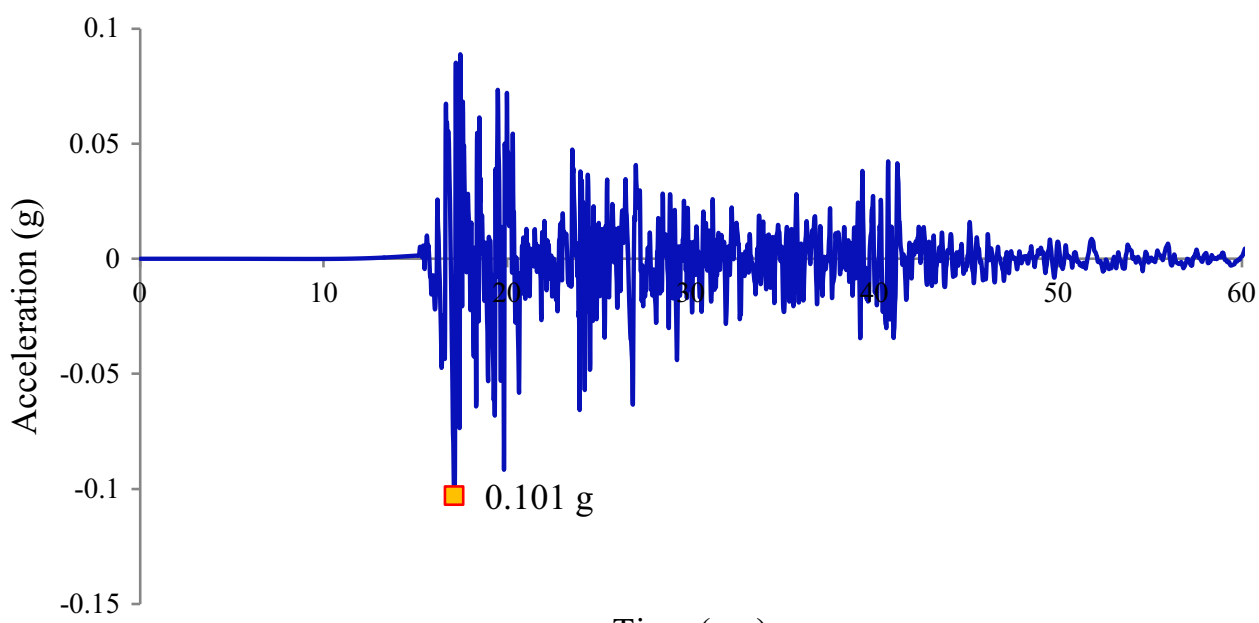

Time (sec)

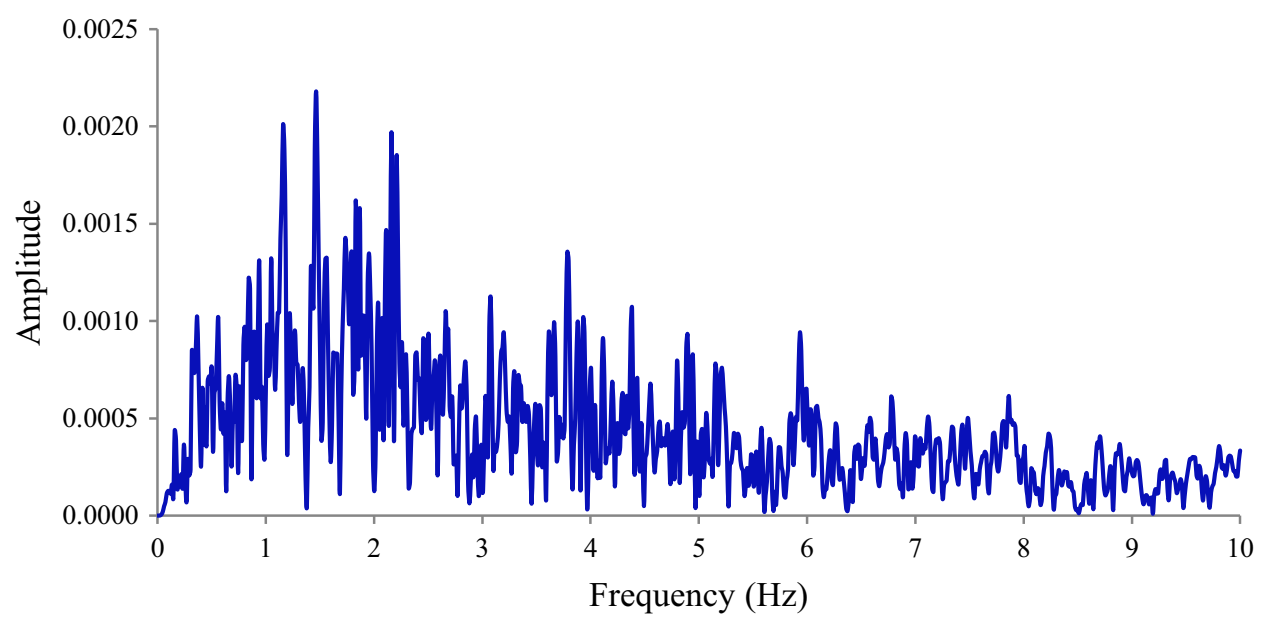

Fig. 8 Fourier spectrum curve of scaled Elcentro1 ground motion at bedrock
Fig. 7 Acceleration time history of scaled Elcentro1 ground motion at bedrock 
Fig. 9 Natural period of buildings with different shear wall configurations: a soil type $S_{b}$, b soil type $S_{c}$, c soil type $S_{d}$ and $\mathbf{d}$ soil type $S_{\mathrm{e}}$
$\mathrm{S}_{\mathrm{b}}$

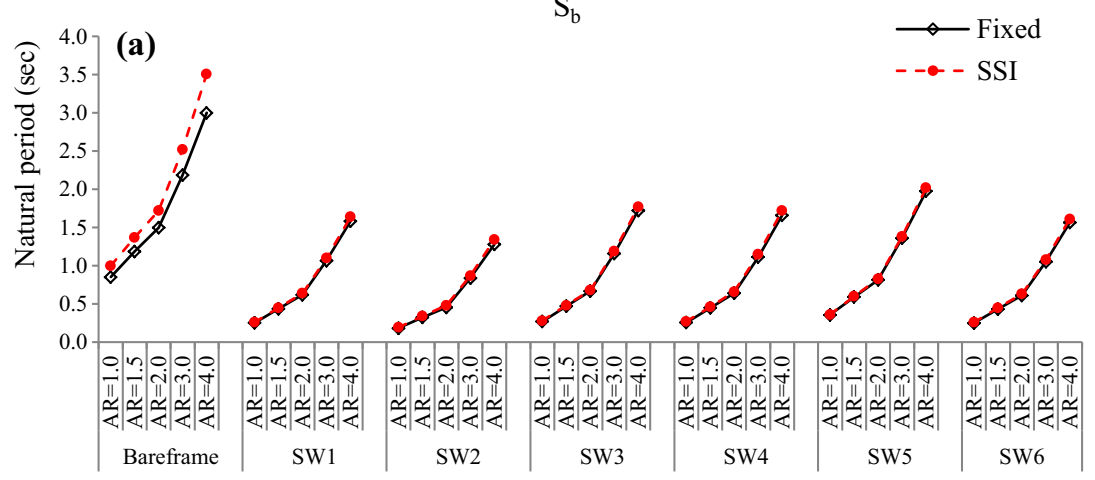

Building configuration

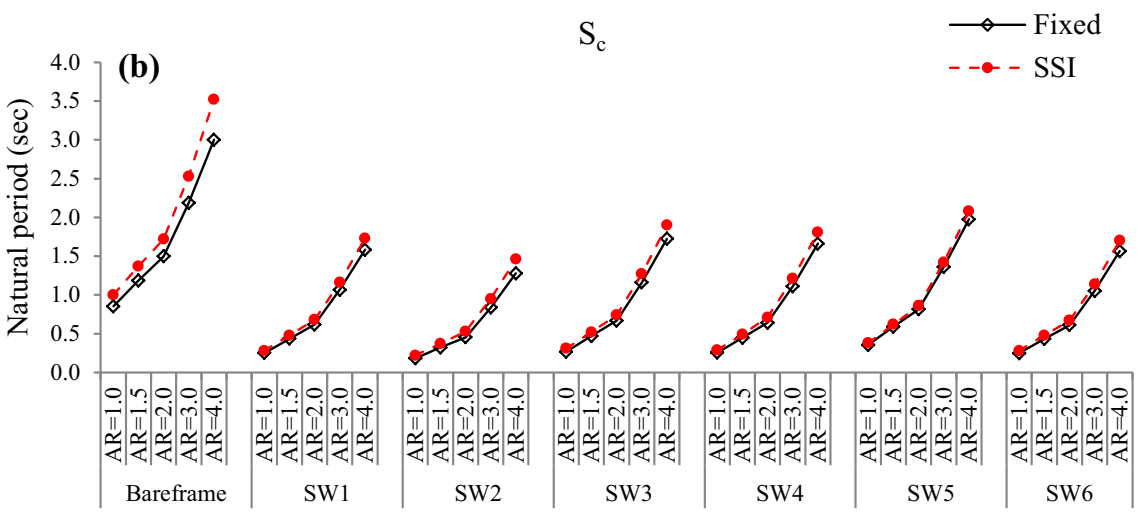

Building configuration

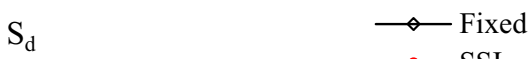

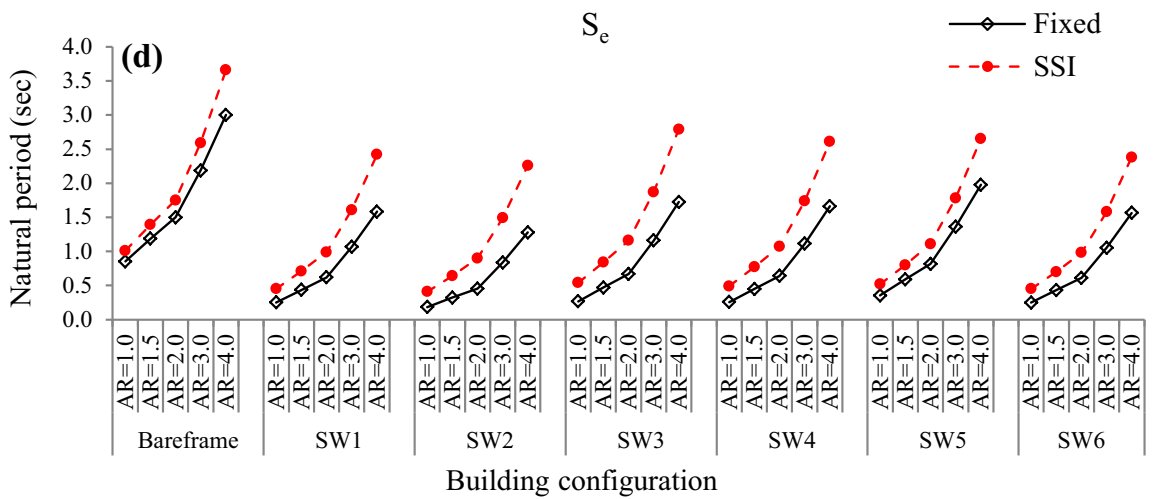


Elcentro1 ground motion is as shown in Fig. 10. The variations in the value of seismic base shear are expressed in terms of total seismic weight (W) of each structure.

The base shear in bare frame buildings is lesser than that in shear wall buildings due to less seismic weight which forms the primary parameter in base shear calculation. Comparing the variation in base shear obtained by considering the fixed base and incorporating the three dimensional SSI effect, it is observed that the seismic base shear computed as per fixed base, which is the conventional practice, is very high. This variation in base shear, between the conventional design practice and SSI, increases with increase in flexibility of underlying soil. The base shear varies in the range of 0.015 to $0.064 \mathrm{~W}$ in bare frame buildings resting on soil. However, for the conventional fixed base condition, it varies in the range of 0.043 to $0.109 \mathrm{~W}$. In shear wall buildings with various shear wall locations and SSI, base shear varies in the range of 0.012 to $0.125 \mathrm{~W}$. But for the conventional fixed base condition, base shear varies in the range of 0.052 to $0.191 \mathrm{~W}$.

Lowest base shear of $0.052 \mathrm{~W}$ is observed in shear wall buildings with SW5 configuration (aspect ratio 3) for conventional fixed base condition. But in the case of buildings with the consideration of underlying soil stiffness, the least base shear of $0.012 \mathrm{~W}$ is seen in SW2 configuration (aspect ratio 4) for $\mathrm{S}_{\mathrm{e}}$ soil type. The highest and the least reduction of 88.32 and $10 \%$ are observed in SW2 configuration over $\mathrm{S}_{\mathrm{e}}$ soil type and SW6 configuration over $S_{c}$ soil type due to the effect of the underlying soil.

For the applied ground motion, SW5 configuration shows the minimum base shear for buildings resting over soil types $S_{b}$ and $S_{c}$. However, with increase in soil flexibility i.e., for $S_{d}$ and $S_{e}$, SW2 configuration shows the minimum base shear.

\section{Roof deflection}

The Fig. 11 represents roof deflection of buildings with various shear wall locations for the conventional fixed base condition and SSI for the applied Elcentro1 ground motion.

It is observed that, SW2 shear wall configuration shows the minimum roof deflection in all SSI cases. Roof deflection increases with increase in aspect ratio and flexibility of underlying soil. Variation in roof deflection values between the conventional fixed base and SSI are more in shear wall buildings for soft soil i.e., $\mathrm{S}_{\mathrm{e}}$ soil type. The least and the highest roof deflections of 0.0312 and $0.1190 \mathrm{~m}$ are observed in SW2 shear wall configuration of aspect ratio 1 for $S_{b}$ soil type and SW6 shear wall configuration of aspect ratio 4 for $S_{d}$ soil type respectively.

Effect of SSI in increasing roof deflection is more prominent in buildings resting over $S_{d}$ and $S_{e}$ soil type as well as in high rise buildings. The high rise buildings with SW6 configuration have remarkable increase in roof deflection due to the effect of underlying soil. The roof deflection in SW2 configuration is least affected by SSI even in the case of $S_{d}$ and $S_{e}$ soil type. An increase of $101.67 \%$ in roof deflection is observed in SW6 configuration (aspect ratio 4) for $S_{d}$ soil type due to the effect of the underlying soil.

\section{Axial forces in column}

Axial force variation in ground floor columns due to earthquake motion may cause the global failure of structures. Axial forces in the corner column of ground floor of the shear wall buildings are as shown in Fig. 12 for applied ground motion.

SSI effect is very less in the axial force of corner column of bare frame buildings. The axial forces obtained for the conventional fixed base condition are higher than those obtained incorporating SSI effect for all the shear wall configurations except for SW6 configuration. Effect of SSI is more prominent in SW3 configuration as compared to other configurations considered. Axial force in the exterior column of ground floor of SW4 shear wall configuration shows the least value for all soil types. The highest axial force is observed in SW5 configuration for soil types $\mathrm{S}_{\mathrm{b}}, \mathrm{S}_{\mathrm{c}}$ and $S_{d}$ and in SW6 configuration for very soft soil (i.e., $S_{e}$ soil type). The highest and least axial force of 1447.31 and $64.68 \mathrm{kN}$ are observed in SW5 configuration (aspect ratio 4) in $S_{c}$ soil type and SW4 configuration (aspect ratio 1) in $\mathrm{S}_{\mathrm{b}}$ soil type respectively.

In general, axial force is reduced due to SSI effect and it is $36.06 \%$ in SW2 configuration (aspect ratio 2) for soil type $\mathrm{S}_{\mathrm{b}}$ and $51.77 \%$ in SW5 configuration (aspect ratio 1.5) for soil type $S_{e}$.

\section{Bending moments and shear forces in column}

Bending moments and shear forces in exterior column of ground floor of shear wall buildings are shown in Figs. 13 and 14 for Elcentro1 ground motion. These figures show the reduction in bending moments and shear forces of ground floor corner column of shear wall buildings with respect to the bare frame buildings. It is observed that shear forces and bending moments are greatly reduced by the inclusion of shear wall in the framed buildings. In general, this reduction in shear force and bending moment is higher for buildings considering conventional fixed base than with SSI.

Variation of bending moment in exterior column of ground floor in various shear wall building configurations as compared to bare frame buildings is as shown in Fig. 13. The least and the highest values of bending moment in 
Fig. 10 Base shear of buildings with different shear wall configurations subjected to ElCentro 1 ground motion: a soil type $S_{b}$, b soil type $S_{c}$, c soil type $S_{d}$ and $\mathbf{d}$ soil type $S_{e}$
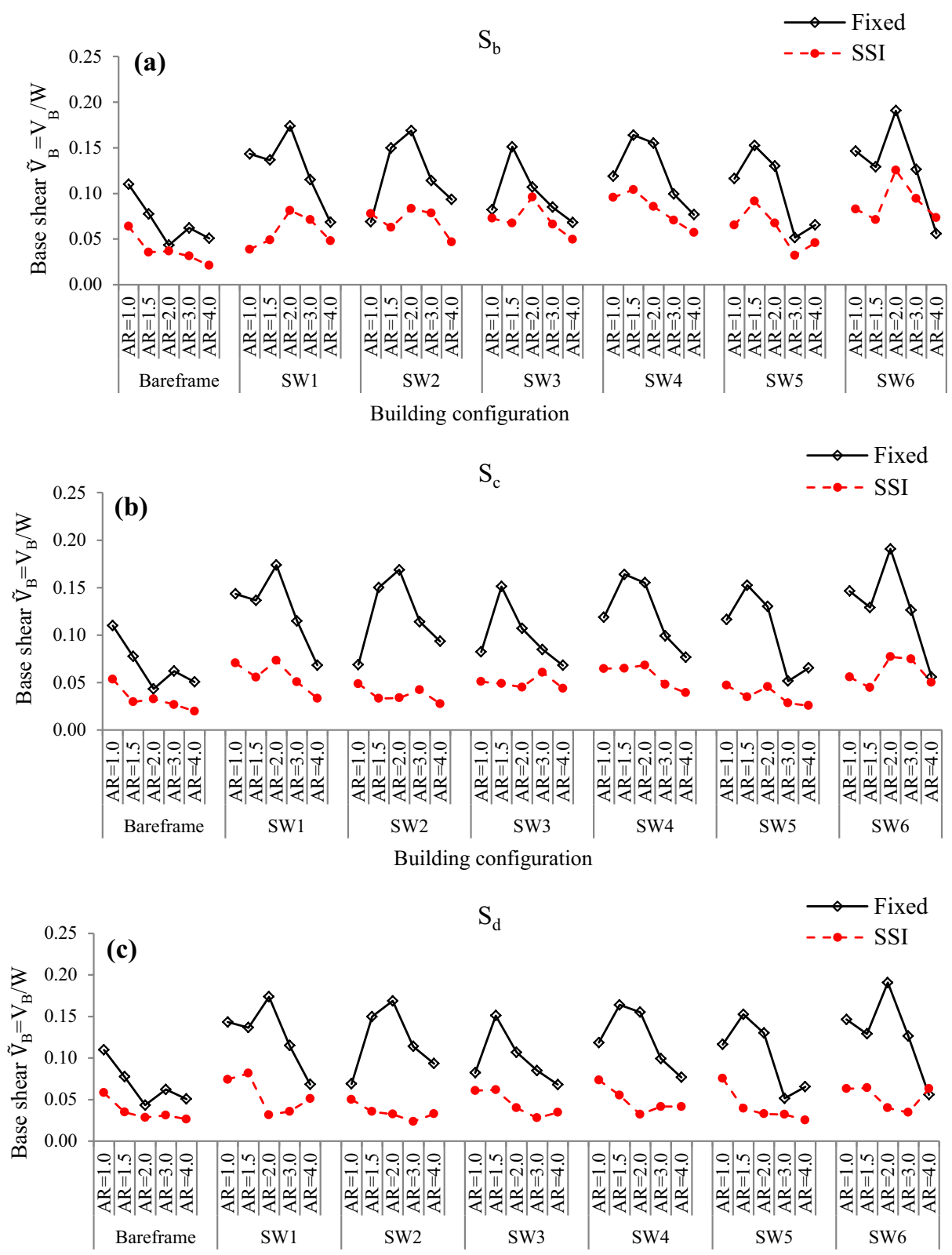

Building configuration

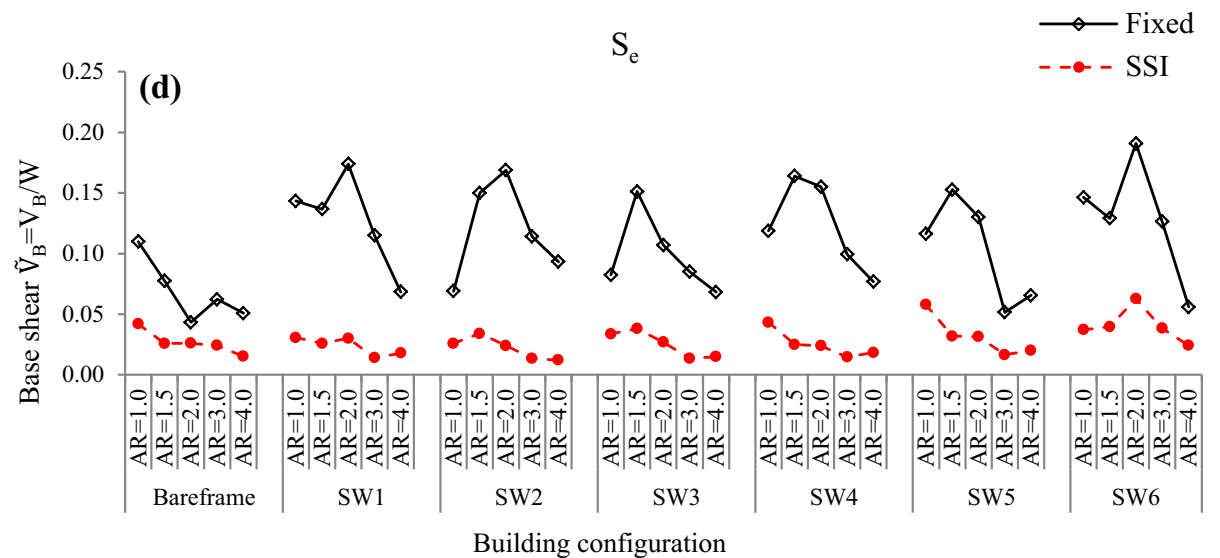


Fig. 11 Roof deflection in various building configurations for Elcentro1 ground motion: a soil type $S_{b}$, b soil type $S_{c}$, c soil type $S_{d}$ and $\mathbf{d}$ soil type $S_{e}$

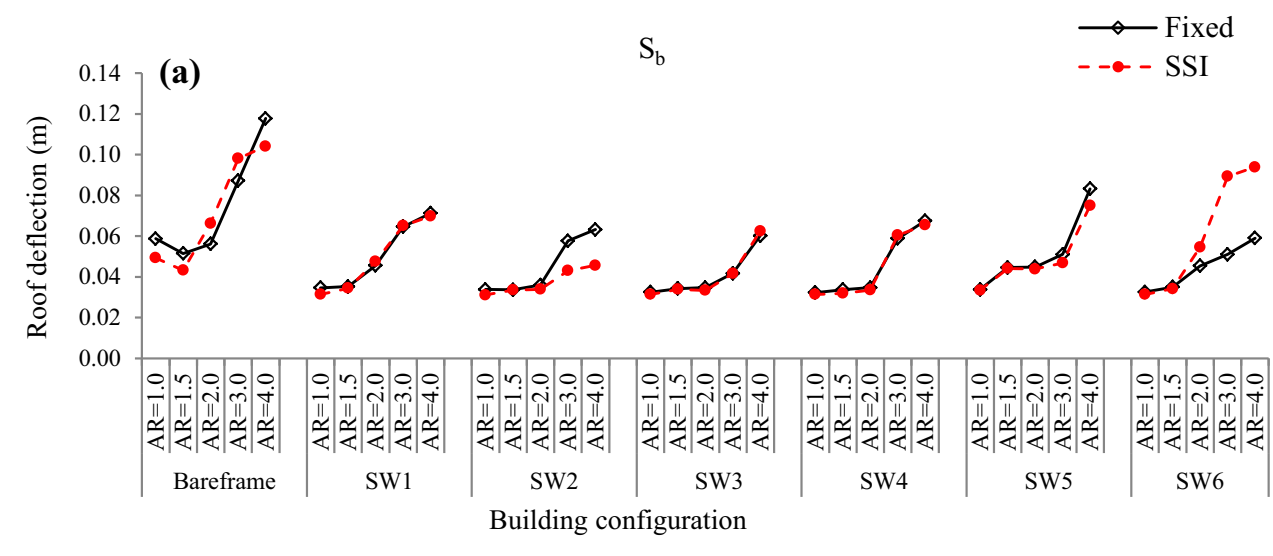

$\mathrm{S}_{\mathrm{c}}$
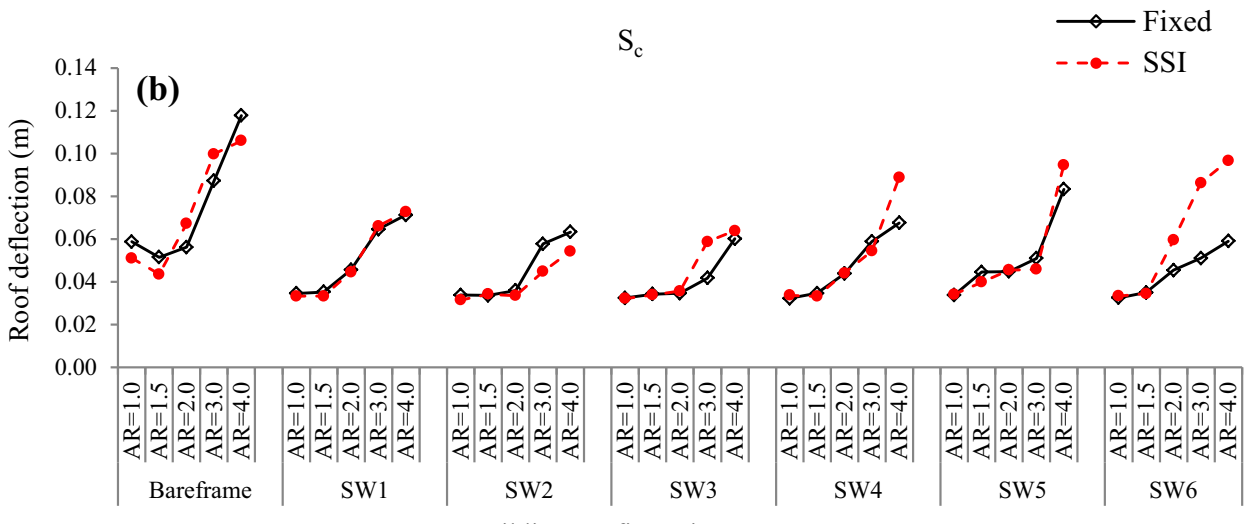

Building configuration
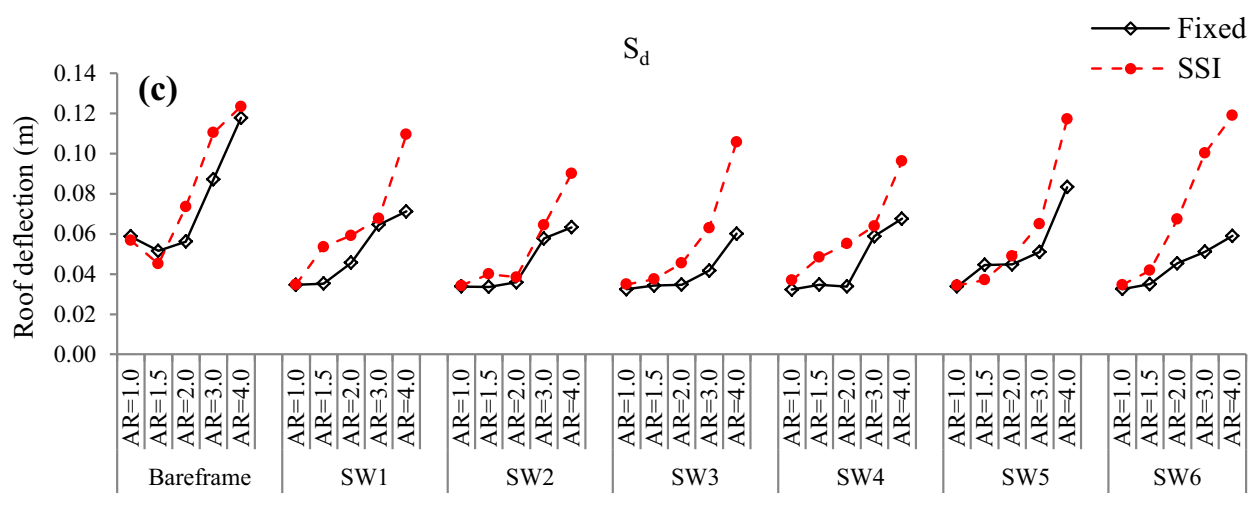

Building configuration

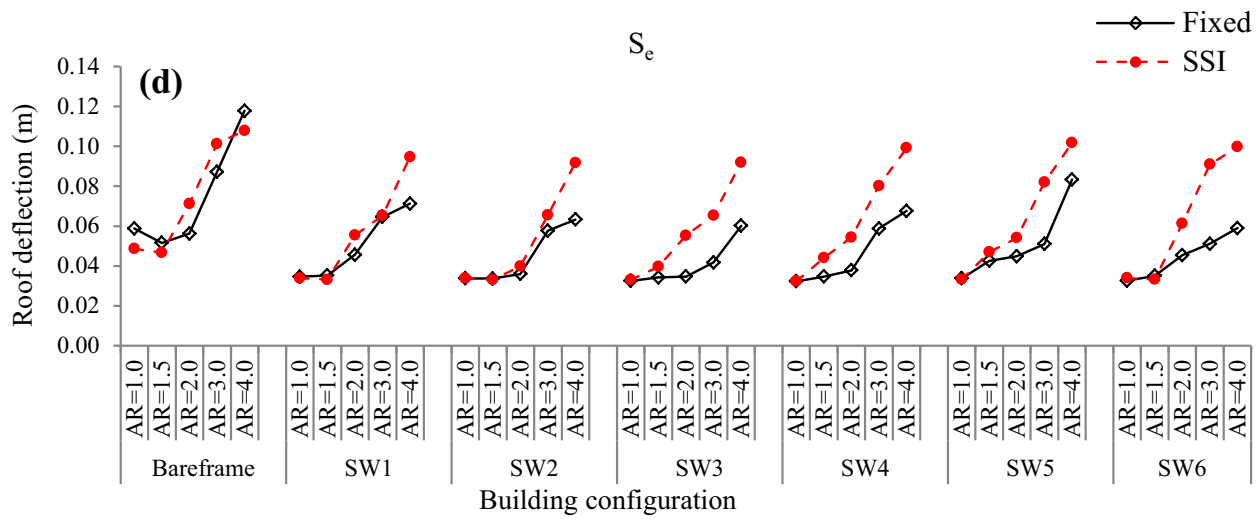


Fig. 12 Axial force in exterior column of ground floor in various building configurations for Elcentro1 ground motion: a soil type $S_{b}$, b soil type $S_{c}$, c soil type $S_{d}$ and $\mathbf{d}$ soil type $S_{e}$
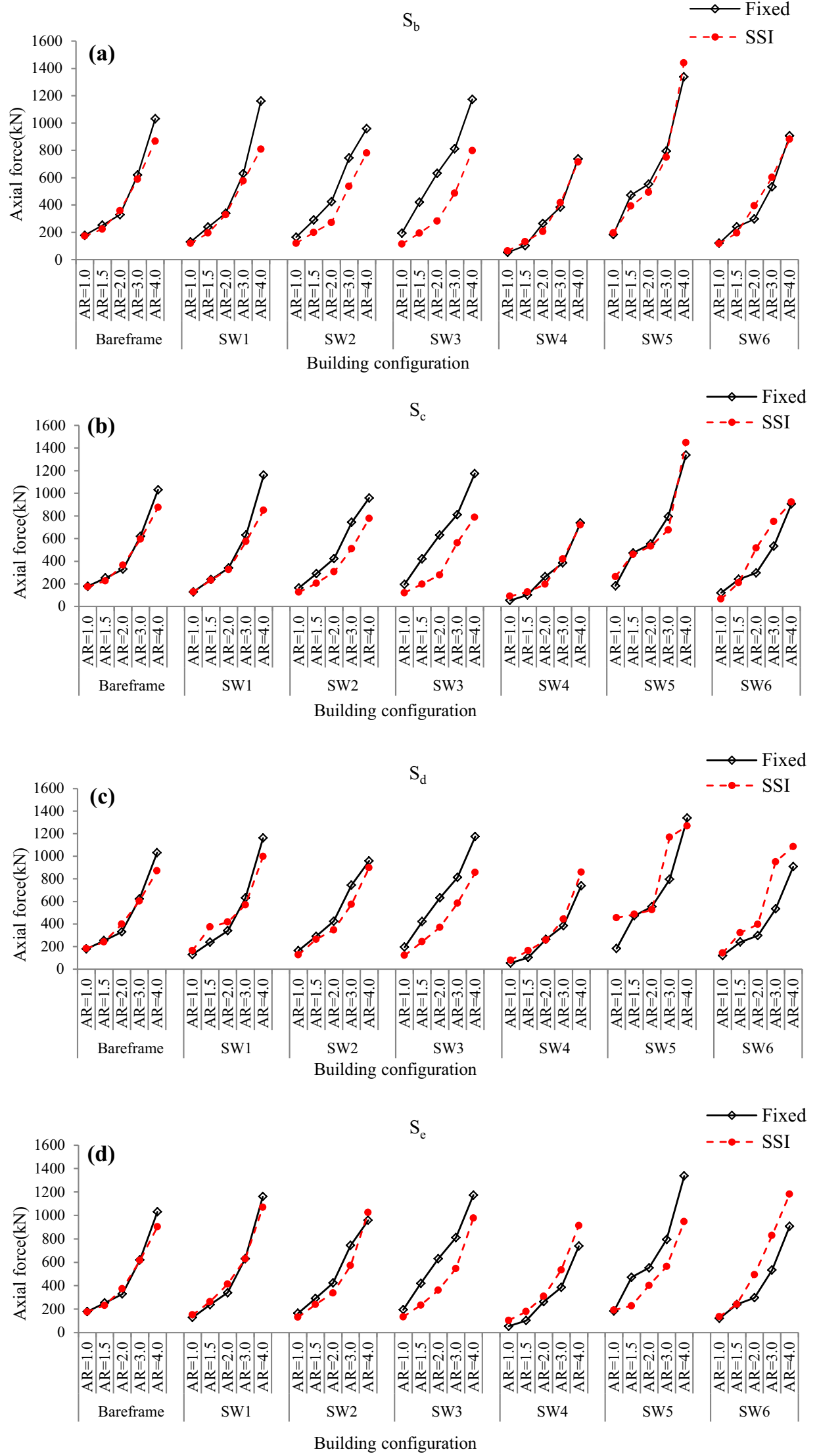
Fig. 13 Variation of bending moment in exterior column of ground floor in various building configurations for Elcentro1 ground motion: a soil type $S_{b}$, b soil type $S_{c}$, c soil type $S_{d}$ and d soil type $S_{\mathrm{e}}$
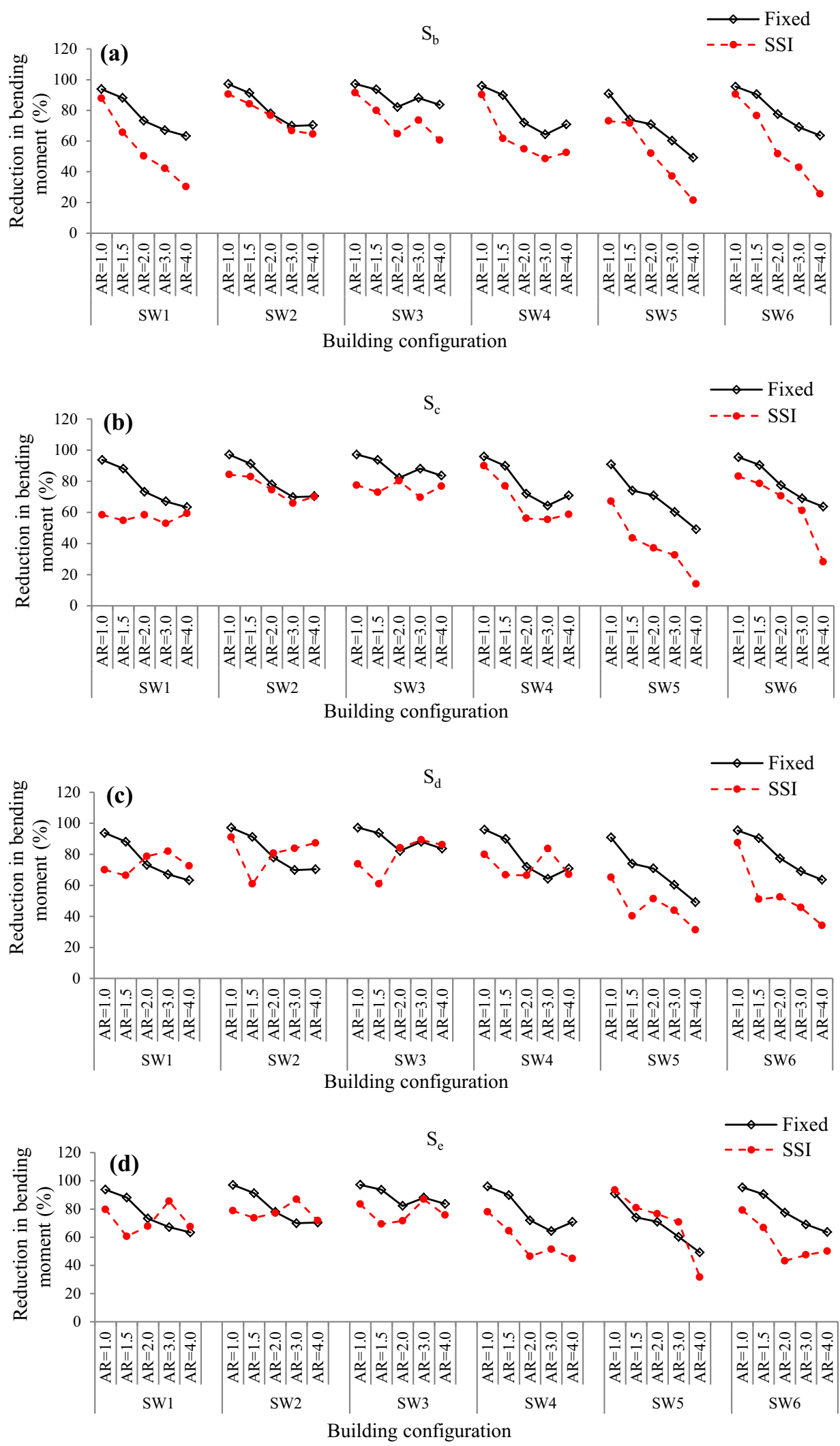
Fig. 14 Variation of shear force in exterior column of ground floor in various building configurations for Elcentro1 ground motion: a soil type $S_{b}$, b soil type $S_{c}$, c soil type $S_{d}$ and d soil type $S_{e}$
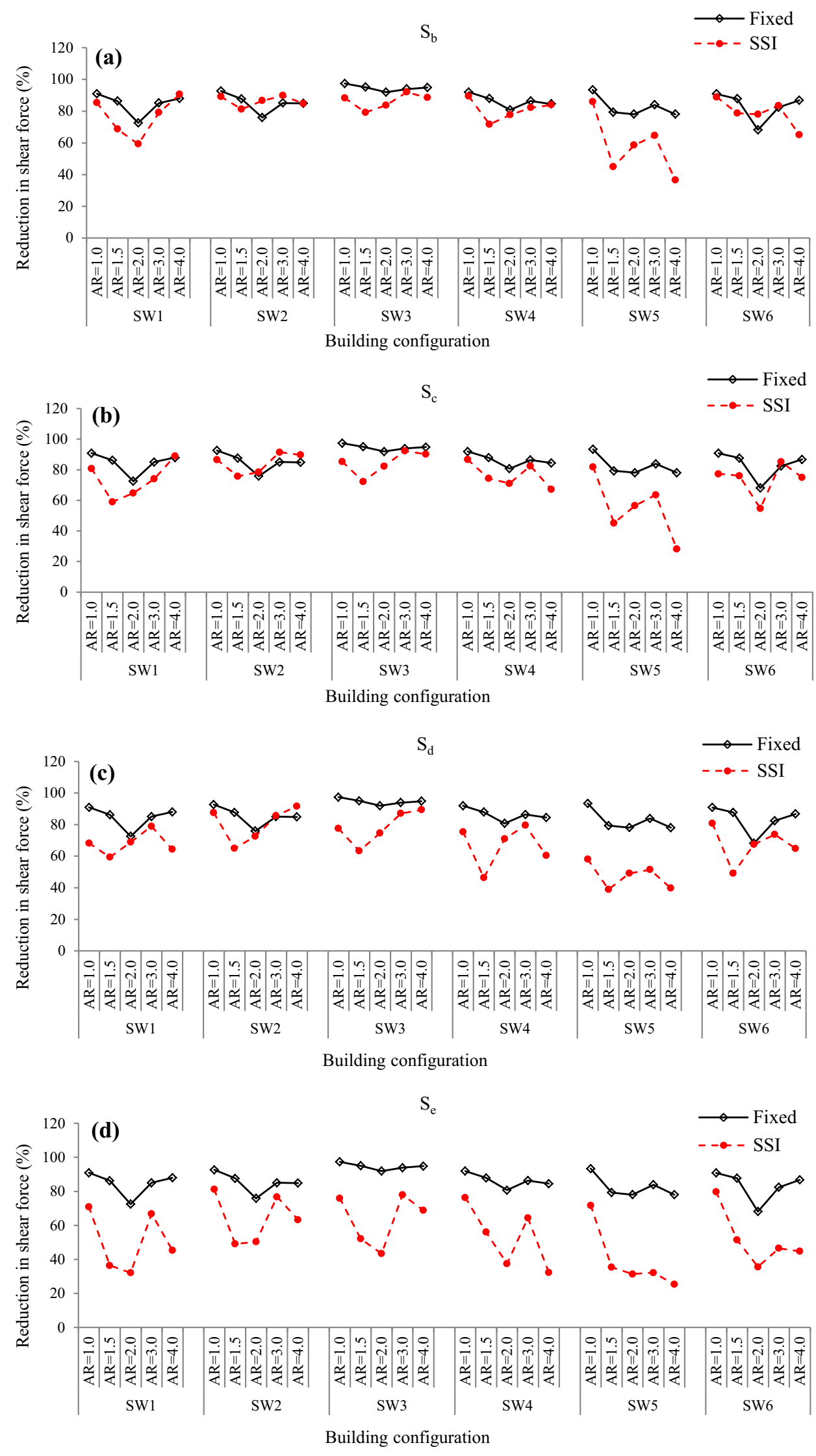
exterior column of ground floor is observed in SW2 and SW5 configuration respectively. From this figure it is observed that, SW5 configuration shows the least percentage reduction in bending moments when compared with bare frame buildings for all aspect ratios and soil types $\mathrm{S}_{\mathrm{b}}, \mathrm{S}_{\mathrm{c}}$ and $\mathrm{S}_{\mathrm{d}}$. However, for $\mathrm{S}_{\mathrm{e}}$ soil type, $\mathrm{SW} 4$ shows the least percentage reduction in bending moments for buildings of all aspect ratios except 4 . The highest percentage reduction in bending moments is observed in SW2 configuration for all soil types. The highest and least percentage reduction in bending moment of shear wall building with respect to the bare frame building are found to be $91.1 \%$ in SW2 configuration (aspect ratio 1) for soil type $\mathrm{S}_{\mathrm{d}}$ and $14 \%$ in SW5 configuration (aspect ratio 4) for soil type $\mathrm{S}_{\mathrm{c}}$.

Reduction in shear force in the exterior column in various shear wall building configurations as compared to bare frame buildings for Elcentro1 ground motion is as shown in Fig. 14. Shear forces are greatly reduced by inclusion of shear wall in the framed buildings. Percentage reduction of shear force in shear wall buildings as compared with bare frame buildings is higher for buildings with fixed base than SSI. SW3 and SW5 configuration in general shows the least and the highest values of shear force in exterior column of ground floor. From Fig. 14 it is observed that, SW5 configuration shows the least percentage reduction in shear force when compared to bare frame buildings for all aspect ratios and soil types. Highest percentage reduction in shear force is observed in SW2 shear wall configuration. Due to SSI, the least percentage reduction of $25.3 \%$ in shear force is observed in SW5 configuration (aspect ratio 4) for soil type $S_{e}$ and highest percentage reduction of $91.6 \%$ shear force is observed in SW2 configuration of aspect ratio 4 for soil type $\mathrm{S}_{\mathrm{d}}$.

\section{Conclusions}

The integrated structure-foundation-soil system was analysed by finite element software LS DYNA based on direct method of SSI assuming linear elastic behaviour of soil and structure. Parametric studies were conducted to determine the effect of SSI by considering different stiffness for supporting soil medium, buildings of different aspect ratios and configurations. The seismic responses of structures are expressed in terms of absolute maximum responses of base shear, roof deflection, axial force, bending moment and shear forces. The responses obtained from SSI analysis were compared with those obtained from conventional analysis assuming the base of structure as fixed. The effect of building configuration and SSI were assessed.

The following conclusions are drawn,
- Fundamental natural period of buildings incorporating the SSI effect is more than that of the same building with fixed-base and at least $23.6 \%$ increase occurs if the underlying soil is soft.

- The variation in natural period due to SSI effect is more when both the building and soil type are either stiff or flexible and less when one of the components is stiff and the other is flexible.

- Base shear obtained for the conventional fixed base condition is very much higher than that obtained in buildings with SSI. This variation increases with increase in flexibility of soil.

- The advantageous locations of shear walls are at corners (SW5) for buildings founded on soil with $\mathrm{Vs}>300 \mathrm{~m} / \mathrm{s}$ and at the core (SW2) for buildings founded on soil with $\mathrm{Vs} \leq 300 \mathrm{~m} / \mathrm{s}$ since the base shear obtained is the least.

- Base shear reduces by at least $62.4 \%$ in SW2 configuration buildings founded on soft soil. Reduction in base shear of at least $29.7 \%$ occurs in SW5 configuration buildings even when the underlying soil is stiff.

- Roof deflection increases with increase in flexibility of soil and the effect of SSI on roof deflection is more prominent in buildings resting over stiff and soft soil.

- The roof deflection is the least in buildings with shear walls placed at the core for all soil types.

- The buildings with shear walls placed at core show the highest percentage reduction in column bending moment and shear force among buildings of all aspect ratios and soil types.

It is concluded that providing shear walls at the core gives a better seismic performance if the structures are founded on soft soil in moderate seismic intensity regions.

Open Access This article is distributed under the terms of the Creative Commons Attribution 4.0 International License (http://crea tivecommons.org/licenses/by/4.0/), which permits unrestricted use, distribution, and reproduction in any medium, provided you give appropriate credit to the original author(s) and the source, provide a link to the Creative Commons license, and indicate if changes were made.

\section{References}

1. Adam M, Chouw N, Estoff O (2005) Significance of soft local site in altering the no-uniform ground motions and the building response. Al-Azhar Univ Eng J 8(1):154-169

2. Alavi B, Krawinkler H (2004) Behaviour of moment resisting frame structures subjected to near-fault ground motions. Earthq Eng Struct Dyn 33(6):687-706

3. Balendra T, Heidebrecht AC (1986) Influence of different sites on seismic base shear of buildings. Earthq Eng Struct Dyn 14(4):623-642 
4. Basu U (2009) Explicit finite element perfectly matched layer for transient three-dimensional elastic waves. Int J Numer Methods Eng 77:151-176

5. Basu U, Chopra AK (2003) Perfectly matched layers for timeharmonic elastodynamics of unbounded domains: theory and finite-element implementation. Comput Methods Appl Mech Eng 192:1337-1375

6. Bhattacharya K, Dutta SC, Dasgupta S (2004) Effect of soilflexibility on dynamic behaviour of building frames on raft foundation. J Sound Vib 274:111-135

7. Dutta SC, Bhattacharya K, Roy R (2004) Response of low-rise buildings under seismic ground excitation incorporating soilstructure interaction. Soil Dyn Earthq Eng 24:893-914

8. Galal K, Naimi M (2008) Effect of conditions on the response of reinforced concrete tall structures to near fault earthquakes. Struct Des Tall Spec Build 17(5):541-562

9. Gazetas G, Mylonakis G (1998). Seismic Soil-structure interaction: new evidence and emerging issues. In: Geotechnical special publication 75, geotechnical earthquake engineering and soil dynamics III. American Society of Civil Engineers, Reston, pp 1119-1174

10. Kobayashi H, Seo K, Midorikawa S (1986) Estimated strong ground motions in the Mexico City earthquake. The Mexico earthquakes 1985, factors involved and lessons learned. In: Proceedings, international conference, Camino Real Hotel, Mexico City, Mexico, pp 97-111

11. Kramer SL (1996) Geotechnical earthquake engineering. In: Prentice hall civil engineering and engineering mechanics series, ISBN 0-13-374943-6
12. Lee SH (2006) Application of the perfectly matched layers for seismic soil-structure interaction analysis in the time domain. Mtech thesis, University of Hawaii

13. Maharaj DK, Amruthavalli A, Nishamathi K (2004) Finite element analysis for frame foundation soil interaction. Electr $\mathrm{J}$ Geotech Eng 9C, Paper 2004-0413

14. Massumi A, Tabatabaiefar HR (2008) A criterion for considering soil-structure interaction effects in seismic design of ductile RCMRFs according to Iranian codes. In: Proceedings, 14th world conference on earthquake engineering (14WCEE), Beijing, China

15. Rajasankar J, Iyer NR, Swamy BY, Goplalakrishnan N, Chellapandi P (2007) SSI analysis of a massive concrete structure based on a novel convolution/deconvolution technique. Sadhana 32:215-234

16. Sivakumaran KS, Balendra T (1994) Seismic analysis of asymmetric multi-storey buildings including foundation interaction and P- $\Delta$ effects. Eng Struct 16(8):609-624

17. Stewart JP, Seed RB, Fenves GL (1998) Empirical evaluation of inertial soil-structure interaction effects. PEER-1998/07, Pacific Earthquake Engineering Research Centre, University of California, Berkeley

18. Tavakoli HR, Naeej M, Salari A (2011) Response of RC structures subjected to near fault and far fault earthquake motions considering soil-structure interaction. Int $\mathrm{J}$ Civil Struct Eng 1(4):881-896

19. Veletsos AS, Prasad AM (1989) Seismic interaction of structures and soils: stochastic approach. J Struct Eng ASCE 115(4):935-956 